\title{
The Meaning of Bird Music
}

\section{Songs of Whose Beauty the Birds Are Consciously Appreciative By Henry Oldys}

WhEN on some dark, overcast night in late September, there comes to the ear from overhead sundry piping or chirping notes, it is easy to recognize them as auditory signals holding together certain flocks of migrating birds on their annual journey to the South. But when one on their annual journey to the South. But when one
of these migrants, while returning to its summer home of these migrants, while returning to its summer home, perches on a twig and, with head thrown back and
throat vibrating, pours out a series of orderly tones, the significance of the utterance is not so apparent.

It is now the well-settled opinion that such utterances do not find their primary stimulus in courtship and mating. Darwin's theory that the choice of mate on the of song in the male, has been sufficiently discredited by Herbert Spencer, St. George Mivart, August Weismann, Herbert Spencer, St. George Mivart, August Weismann,
and others, and is now discarded by virtually all the and others, and is now discarded by virtually all the
leading students of evolution. It is, of course, undeleading students of evolution. It is, of course, unde-
niable that songs, like plumage displays, are used in connection with courtship; but such use is merely an incidental one, as it is with human beings, and is probably seldom, if ever, the determining factor in the female's choice of a mate. Moreover, even on Darwin's assumption that the finest singers mate most easily and so frequently than singers of a lower grade, thus gradually improving the race musically, it is doubtful if such progenial transmission of musical qualities would prove to be the chief means of progress, in view of the important part played by acquisition of song by imitation in musical improvement among birds. It is well known that the singing powers of canaries are not produced by breeding from gifted ancestors, but by associating the birds with unrelated superior singers known as "campaninis," which are kept for this special purpose and which often command very high prices. Wild birds similarly improve their singing by imitation of better singers of their own species, as is evidenced by severa direct examples of such imitation which have come to my personal attention. Furthermore, few female birds sing; and it seems most probable that if they possessed sufficiently discriminative ears to appreciate and select the finest singers among the males, they would themselves become singers.

But if Darwin's theory of sexual selection be inadequate to account for the development of bird song from the original unmusical ejaculations to the present melodies, what is the true cause of such development? The simple and natural answer is that musical evolution among birds is due to the same causes that have produced musical evolution in man, especially as the results of the two streams of evolution show marked resemblances.

It is customary, at the present time, to deprecat any interpretation of animal behavior in terms of human behavior-to attempt to explain all actions of the lowe animals on the basis of different psychical processes from those producing similar actions on the part of the human species. This attitude expresses the natural reaction against the popular tendency to overhumanize the lower animals. Unscientific minds assume for the behavior for all animate beings the same mental causes that would produce such behavior in themselves; but scientific minds, in combating this error, transgress equally in the opposite direction. Such reactions generally go too far. Thus the constant use of consecutive fifth and octaves for several centuries in the earlier stage of our modern music has led to a rabid proscription of such harmonic progressions; and a later overindulgence in the chord of the diminished seventh has brought that attractive and serviceable combination of tones into almost equal disrepute. Hence, the complete humanizing of the animal world by ignorance has led to the complete dehumanizing of it by learning. It is the reverse swing of the pendulum.

Disregarding the many physiological likenesses between ourselves and these fellow creatures of a lowe evolutionary stage, science emphazises the physiological differences and makes them the basis for an almost totally different psychological method of arriving at results. Yet, as in the human mind, instinct mingles with reason, so in the animal mind reason mingles with instinct. When we are confronted with two musical evolutions paralleling each other remarkably, the most rational supposition is that such evolutions are alike in their origin and in their sustaining causes. The birds display evidence of enjoyment of their songs; they manifest a proneness to sing freely when happy and $t$ *Fiom the American Museum Journal, published by the American Museum of National History, New York. be mute when unhappy; they show a seeming interest in the performances of more accomplished singers, and an apparent desire to acquire phrases and tones that excel their own; they exhibit much knowledge of the value of rhythm, of melody, of tonality, and even of sequence of related musical phrases; in all these things paralleling ourselves. An explanation of these attributes on any basis but that of musical appreciation (by which human attributes of the same kind are explained) would be most complicated, far-fetched, and altogether unsatisfactory. The rule adopted by investigators of the psychology of the lower animals is never to accept an explanation based on higher psychical processes when one based on lower psychical processes may be made. A useful rule; but it is easily metamorphosed into a rule never to accept a simple, direct explanation when a more complicated, indirect one may be assumed. And many of the interpretations of psychologists seem to be governed by this derived (and pernicious) rule.

As with man, so with birds, the development of musical appreciation ranges from zero to the maximum. While the impulse to express emotion vocally is common to many creatures, such expression in musical form is limited to comparatively few. The dog barks his joy, the bull roars his definace, the cat purrs her content, the hog grunts its satisfaction, but utterances of this character can by no legitimate stretching of the term be described as music. So, too, among birds the rattle of a kingfisher, the scream of an eagle, the squawk of a parrot, cannot be classed as musical performances. Nor is there any physiological line of demarcation between musical and non-musical birds. The crow and grackle, although properly classed structurally with the Oscines, or singing birds, are lacking in musical expression; while the wood pewee, dove, bobwhite, and others beyond the pale physiologically, express themselves musically, the wood pewee taking high rank in this regard.

Even the common barnyard cock will occasionally express his exuberant feelings in true melody, as in this paen with which I heard a Maryland cock greet the dawn on a November morning:

\section{:}

and in which the final descent of the gamut was accomplished by distinct steps, unblurred by any portamento, or slur, and in good strict time. Many of the Oscines that may properly be classed as melodists hold their title by a very slight grip. The lisping or buzzing songs of most species of warblers, the incoherent utterances of purple finch, goldfinch, warbling viero, junco, and like singers, the twittering chirpings of swallows, the monotones of nuthatch and chipping sparrow, and the indeterminate notes of house wren, indigo bird, and English sparrow (in his rare musical moods) - these performances, although of ten pleasing to the ear, are almost entirely lacking in melody, as known and enjoyed by man, while the dickcissel expresses his emotions in articulations that seem to belong to speech, rather than song.

On the other hand, some of the avian melodists are entitled to high rank as musicians, even when judged by human musical standards. Many of their productions, although brief, excel in melodious beauty the best efforts of some primitive human races, and a few are worthy of a place beside the melodies of the civilized world. Here is an attractive passage $e^{l}$ in which a theme in a minor key is followed by the same theme in the relative major key, with a change from piano to forte that gives a distinct touch of brilliancy:

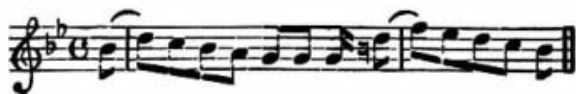

This is not, as might be thought, an extract from the note book of Mozart, Bach, or Mendelssohn, but an excerpt from the song of a rock thrush (Monticola saxicola) I heard in the Worthington Aviary at Shawnee-onDelaware, Pennsylvania, four or five years ago. The notes were perfectly true to pitch and were given in a quality of tone that was exactly that of the human whistle. The attendants at the aviary had picked up the bird's phrases, and during my three days there I 1Although the fact is unimportant, it may be stated that all the bird songs given in this
than they are here written. could never tell without inquiry whether the bird or an
attendant was responsible for any particular rendering of them I happened to hear.

Like the true little musician that he was, the thrush voided monotony by varying his utterances, sometimes with different themes, sometimes with different combinations of themes. His ingenious use of the second theme of the song quoted above appears in the following notations of some of the combinations:
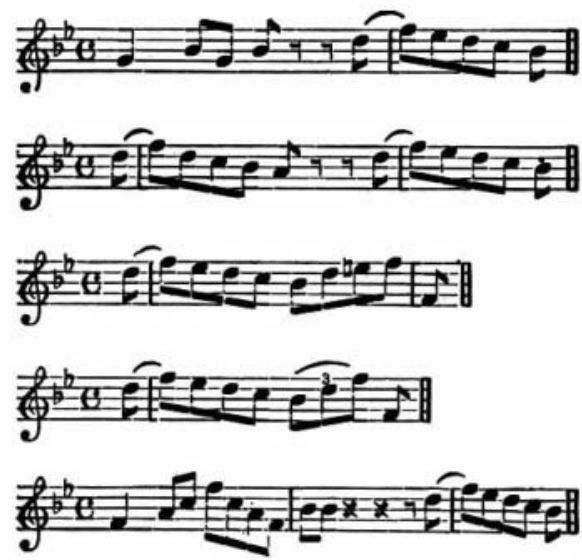

But while the theme that plays so prominent a part in the examples I have given of the bird's music was favorite with him and was freely used, he had several other phrases in which it did not appear. The following one will be sufficient to indicate the general character of the rest of his music:

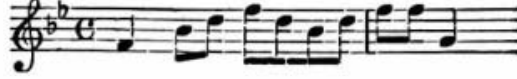

It will be apparent to any musician, of however humble rank, that the music here written (and it is an exact transcription of the notes sung by the bird) is perfectly comparable to our own music of this twentieth century; and not only in the use of the same scale, but in rhythm, melodiousness, and harmonious balancing of phrases. Careful examination will disclose several effective touches, such as the use, in one of the combinations given above, of the $\mathrm{E}$ before the following F's The rock thrush is found in southern Europe, and if I may safely judge from my own experience with this one individual bird and from the rank accorded the species by some observers of it in its wild state, I should say that it is of all European birds the most melodious -using the term in its proper sense and not in the loose way in which it is generally handled by a carelese public. Its chief rival seems to be the European blackbird (Merula merula). Personally I have little knowledge of the singing of the blackbird, although I have noted one or two utterances from some in America zoölogical collections that indicated the high musical character of the bird in its native wilds. I am able, however, to reproduce three blackbird songs of a very choice quality musically, which were recorded at Sèrvres, France, a few years ago by an accomplished musician and lecturer on music, Mrs. Amelia von Ende:
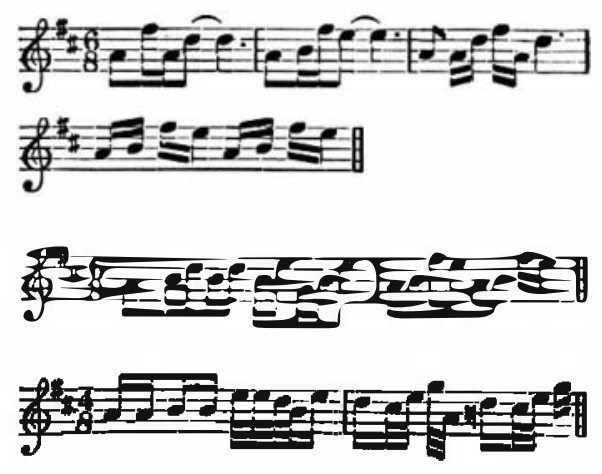

These three songs disclose a strong feeling for harmony as well as for melody. The alternation of tonic and dominant harmony in the first is very effective, while the pleasant modulation to $\mathrm{E}$ minor in the second is quite satisfying. Particular praise must, however, be accorded to the third song, which presents an attractive, sprightly, and well-developed theme.

But it is not necessary to cross the ocean to obtain examples of good music from birds; our own land is the home of some of the best of avian musicians. I have secured several four-phrase songs from our own thrushes 
which in beauty of melody and arrangement of themes surpass all other avian music that has come to my attention, and we have other species that take high musica rank. The song sparrows furnish melodies enough to equip nearly every member of the woodland chorus with a different song for each. Some of these songsparrow themes are very satisfying. Here is one I heard in northern Ohio last spring:

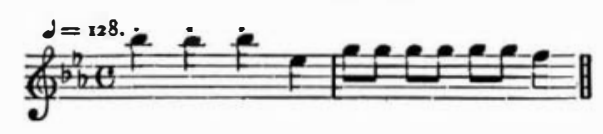

This, although simple, is a very pleasing and melodiou phrase, one that no human musician need be ashamed to borrow for incorporation into some more elaborate composition of his own. And let me say here that our woods and fields are full of suggestive themes for the enterprising musician who awakens to the fact that man has no monopoly of melody. One, at least, of the fraternity recently had his eyes opened to this wealth of musical material, and the result of his discovery is book of songs about birds in which the melody of each song is made up of themes furnished by the bird to which it relates. Some of these songs are very beautiful.
More remarkable than the union of related phrases in sequence by one bird are those performances, occasionally to be met with, in which two related phrases are sung antiphonally by two separate birds. The meadow larks of the eastern half of the United States (Sturnella magna) are especially prone to sing duets of this kind. From forty or more such meadow lark duets that I have noted I here reproduce one sung by two that I have noted I here reprod
birds on my own place last March:

\section{$=0$}

Were the first bird saying, "I love to sing," and the second rejoining, "So I perceive," the effect of phrase and answer would not be more marked.

From such examples of bird music what are we to conclude as to the meaning of bird song? We find some of the birds uttering musical phrases and sequences of phrases that are governed in their construction by rules that govern the construction of our own musical compositions-that conform to those constructive principles that are developed by musical taste in man. Melody, rhythm, harmony, and tonality combine to make them pleasing to our ears in precisely the same way that human music appeals to us. To account for thi phenomenon by a theory of chance coincidence require a degree of credulity that is immense. That a bird should so combine notes as to produce human music accidentally is as incredible as that it should so combine articulate sounds as to form human speech accidentally. To assume that birds are the unconscious instruments of a higher power made to produce such performances as man alone can appreciate and enjoy, is to return to the long-abandoned attitude under which the stars were regarded as mere points of light, created for the purpose of relieving man of absolute darkness on moonles nights. There remains only the idea that birds sin songs of whose musical beauty they are consciously appreciative. This is the simplest and most plausible interpretation of the matter; and if we are brave enough to disregard that bugbear of the average psychologist anthropomorphism, we shall understand that birds share with man an intelligent appreciation of music, share with man an intelligent appreciation of music,
the difference being one of degree, not of kind. We may not comprehend the full philosophical significance of our own musical emotion, but we may safely rest in th assumption that whatever light we have in this respect equally illumines and makes plain the meaning of bird song.

\section{Artificial Eyes \\ Their Early History and Modern Improvement \\ By Dr. Mary Davro}

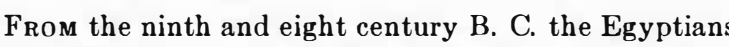
were in the habit of investing their mummies in cases or cartons which formed a sort of armor for the defunct person, and were composed of several pieces: a "boot" into which the feet were inserted, a painted and carved casing for the chest, and over the face a mask representing the features of the deceased, with his blue or black ceremonial wig. Specimens of these masks are to be ceremonial wig. Specimens of these masks are to be
found in various museums. They are composed of found in various museums. They are composed of
several thicknesses of fine cloth pasted together, pressed several thicknesses of fine cloth pasted together, pressed
in a mold, and covered with a layer of stucco or plaster fashioned by the artist into a likeness of the dead person

Dr. Coulomb has in his collection a beautiful funera mask of this sort, dating from the first century of the Christian era and furnished with very pretty artificial eyes. The sculptors of ancient times, too, adorned their statues with materials more or less rare, such as wood, marble, ivory, lapis-lazuli, and so forth.

At first the Egyptian embalmers enucleated the

At first the Egyptian embalmers enucleated the
eyes of corpses and then poured plaster or white wax eyes of corpses and then poured plaster or white wax
into the orbits in order to inset a precious stone, such a obsidian, for example. Then later they substituted for the wax or plaster shells of silver or other metal, sometimes enameled in white and perforated in the center with a hole representing the pupil. But neithe the Egyptian embalmers nor the Greek and Roman sculptors ever provided the living with an artificial device to take the place of a lost visual organ. Th first authentic test which mentions the prothetic eye the passage in the Talmud when it is related that Raff Ismael had made for a young girl an eye and a toot of gold in order to embellish her. No other information upon this subject has been discovered either in the Middle Ages or the Renaissance. But artificial eye of enameled gold are described and pictured in the works of Ambroise Paré. These, which were not very widely used, were then made by jewelers; and in case one of these could not be lodged in the orbit, he even one of these could not be lodged in the orbit, he even
recommended another apparatus "made of iron wire recommended another apparatus "made of iron wire
flattened, bent, and covered with velvet or taffetas, having one side flat that it may not wound, and the other covered with wrought leather, to which the painter gives by his artifice the image of an eye. When this is done it is placed over the orbit. But the said wire can be extended and bent like those which are used to wear to hold their hair in place. It will pass above the ear around half of the head."

In 1601 a Hungarian doctor, Jessenius, speaks in his Surgical Institutions of a Florentine jeweler who manufactured, at Venice, artificial eyes of glass and sold them for as much as 6 or 7 crowns. In an extent specimen, made in Venice, and dating from 1580, the sclerotic is white, the iris brown, and the pupil black, but the ensemble does not give a very good illusion of the anterior chamber of the natural eye. The shell of glass, which is painted on the concave side, this being then covered by a thin plate of polished lead, seems to have been by a thin plate of polished lead, seems to have been
fashioned upon a grindstone. The lead covering had fashioned upon a grindstone. The lead covering had
the double purpose of preventing irritation of the the double purpose of preventing irritation of the
"stump" and of preventing the tears from dissolving the colors.

Later, from the middle of the seventeenth century, the art of the ocularist doubtless declined at Venice, since we find that the heterophthalmic of two worlds provided themselves almost exclusively in France, and especially at Paris, with the crystal eyes which were sold on the Pont Neuf as early as 1682. History, moreover, has preserved for us the name of some of the moreover, has preserved for us the name of some of the most celebrated French specialists of the epoch; among
others the Parisian Hubin or Hubins, of the "Rue Saintothers the Parisian Hubin or Hubins, of the "Rue Saint-
Denys, opposite the Rue aux Ours," his competitor, the sieur Le Quin, established in the Rue Dauphine, and a remarkable artist who exercised his profession at Nevers towards the middle of the eighteenth century, and to whom some authors ascribe (wrongly, however) the invention of the eye made of glass. The fame of certain ocularists of the French capital even extended beyond our frontiers, as is testified to in a memoir by the German physician Adam Haug. Raux, in particular, German physician Adam Haug. Raux, in particular, "enameler in ordinary to the king, Rue aux Juifs,"
imitated perfectly "the form, the color, and the brilliance" of the natural eye by the aid of various Venetian enamels combined with metals.

It is obvious, therefore, that the technique of the ocularist had made remarkable progress since the day of Ambroise Paré. This art continued to perfect itself with the Anzous, father and son, and above all with the "artist oculist of the king" Charles François Hazard so that a contemporary could write in 1904: "In the focus of M. Hazard's lamp you will see born the crystalline, the uvea, the iris, the most imperceptible veins. At midday you order from him the eye you lack, and after dinner you go into society with a perfectly matched pair of eyes!"

In spite of the exaggeration of these lines, Hazard, who died at 54 in 1812 was certainly one of the most skilful ocularists of his time. His nephew and pupil, Hazard Mirault, who published the first Practical Hazard Mirault, who published the first Practical
Treatise on the artificial eye in 1818 also acquired a brilliant reputation. Up to this time glass had been used almost exclusively in the manufacture of prothetic eyes; but since this material off ered many inconveniences Demmenie, an Amsterdam glass-blower, substituted enamel for it, towards the year 1840; and although since then there have been many attempts to replace it by more resistant plastic substances-celluloid for example-nothing better has yet been found. Even the example-nothing better has yet been found. Even the
rubber eyes, advised in 1916 by M. M. Lemaitre and Tevillières, do not seem able to dethrone eyes made of namel

Under the action of fire, enamel, or the silicate of potash and lead, takes on, in fact, a remarkable polish which imitates the sheen of the natural eye; the constant friction of the lids does not wear it away too fast; tears can scarcely dissolve it, and it does not irritate the ocular mucous membrane. Moreover, by the the ocular mucous membrane. Moreover, by the
addition to this crystal of various metallic oxides we are enabled to imitate the smallest details and the most delicate tints of the sclerotic, the iris, or the pupil.

Until about 1850 Paris practically monopolized the industry. But at that time Ritterich introduced the manufacture of artificial eyes into Germany and Austria, where it became localized at Prague, Saalfeld, and Leip- zig. Before the war the ocularists beyond the Rhine competed briskly with our own in the world market and even in France. However, the heterophthalmic nearly always abandon the German specimen because iris has the same color tone when seen at an angle is when the saze at directly, while in the German eye a ayer of white ena completely masks it. Then it nearly always has edges, rough from the grindstone, which irritate the stump, which often remains sensitive after the enucleation, from which headaches may result. Furthermore its enamel is highly charged with lead and becomes sullurized with use, while at times it even bursts in the socket of the eye because of the dilatation of the air confined between the two shells, provoking in such case an abundant hemorrhage.

To remedy the inconvenience of sharp edges the American Borsch of Philadelphia and the Hollander Snellen devised about 1,900 eyes with double walls which do not wound the bottom of the orbit. A little later, our compatriot, Dr. Coulomb constructed eyes with thick edges which are spreading, presenting in section the form of a tear. Lighter than those with a double shell they can, furthermore, be retouched after being made which helps towards perfect adaptation But let us consider the work of a Parisian artist, M. Einius, whom the enamelers of the famous old days would not have refused to accept as a worthy fellow craftsman, and who was kind enough to unveil the arcana of his art to us in a recent visit to his studio. The principal tool of the modern ocularist is a sort of enameler's lamp. This consists of a small tin reservoir provided with a lid at the top. At the base of this receptacle three small brass tubes are soldered, each about 20 centimeters ( 8 inches) long, and recurved towards the lamp at their extremety. A cotton wick is placed in each of these burners and the reservior is then filled with gasoline. Then there is placed in front of the burners a branched piece or fork formed by a brass conduit which communicates across the table with a bellows worked by a pedal. Into this tube lead pipes are soldered, curving towards the burners and terminating in other tubes, of brass, to which are attached small glass blow-pipes. Sometimes gas takes the place of the enameler's lamp. The air from the bellows escapes from the recurved fork, which directs it upon the burners. A small box of sheet-iron completely surrounds the latter, protecting the operator from the heat.

The operator works by artificial light and almost in obscurity so as to clearly observe the entire flame of his blowpipe and not mistake one color for another, which would happen if it was fully illuminated by solar light. Working his bellows by his foot he blows the air upon the burners, so that the flame is driven horizontally in front of him. When it becomes blue (an indispensable condition of success, since the white flame is too hot, spotting the enamels and modifying the colorations) he throws its jet upon the part he wishes to heat. He begins with a crystal tube to whose orifice he fuses a tiny drop of enamel of the desired shade. He brings 